\title{
Relearning Old Lessons for the Future of Food- By Bread Alone No Longer: Diversifying Diets with Fruit and Vegetables
}

\author{
John D. H. Keatinge, Farid Waliyar, Ramni H. Jamnadas, Ahmed Moustafa, Maria Andrade, Pay Drechsel, \\ Jacqueline d'A. Hughes, Palchamy Kadirvel, and Kartini Luther
}

\begin{abstract}
Diversifying diets and agricultural enterprises with fruit and vegetables is a potent weapon in the current global battle against malnutrition and poverty. Agricultural science can contribute substantially to enhance the development prospects and health of not only disadvantaged and vulnerable individuals at one end of the spectrum but also the growth and equity of national economies at the other. Moreover, with relatively simple applied research, new crop species and technologies can rapidly enter the development pathway to benefit even the poorest people or nations. More upstream research can help to guard fruit and vegetable production against the vagaries of potential climatic uncertainty, which is projected to become more prominent over future decades. However, historical and continuing widespread underinvestment in fruit and vegetable research and development from the national to the global level may severely compromise the world's ability to use such highvalue species for crop diversification and as a major engine of development growth to ensure global food and nutritional security.
\end{abstract}

J.D.H. Keatinge, J.d'A. Hughes, P. Kadirvel, and K. Luther, AVRDC The World Vegetable Center, PO Box 42, Shanhua, Tainan, 74199 Taiwan; F. Waliyar, ICRISAT, Patancheru 502 324, Andhra Pradesh, India; R.H. Jamnadas, ICRAF, United Nations Ave., PO Box 30677, Muthaiga, Nairobi, 00100, Kenya; A. Moustafa, ICARDA-APRP, PO Box 13979, Dubai, U.A.E.; M. Andrade, CIP, Apartado 1558, Lima 12, Peru; Pay Drechsel, IWMI, 127, Sunil Mawatha, Pelawatte, Battaramulla, Sri Lanka. Received 21 Sept. 2009. ^Corresponding author (dyno. keatinge@worldveg.org).

Abbreviations: AVRDC, Asian Vegetable Research and Development Center; CGIAR, Consultative Group on International Agricultural Research; CIP, Centro Internacional de la Papa, International Potato Center; CWANA, Central and West Asia and North Africa; GAP, Good Agricultural Practices; HIV/AIDS, human immunodeficiency virus/acquired immunodeficiency syndrome; ICARDA, International Center for Agricultural Research in the Dry Areas; ICRAF, World Agroforestry Centre; ICRISAT, International Crops Research Institute for the Semi-Arid Tropics; IITA, International Institute of Tropical Agriculture; IPPM, Integrated Production and Protection Management; IWMI, International Water Management Institute; NARES, National Agricultural Research and Extension Systems; QTL, quantitative trait loci; WHO, World Health Organization.

$\mathrm{M}$ ALNUTRITION is the most chronic and pressing agricultural and human health problem of the 21st century. Undernutrition, micronutrient malnutrition, and unbalanced overnutrition with excessive consumption of carbohydrates and fats affect at least one third of the world's population in a negative manner and impinge on both longevity and the quality of life with good health. Yet in different regions of the world, in developing and developed countries alike, a similar change in diet is occurring:

Published in Crop Sci. 50:S-51-S-62 (2010)

doi: 10.2135/cropsci2009.09.0528

Published online 28 Jan. 2010.

(C) Crop Science Society of America | 677 S. Segoe Rd., Madison, WI 53711 USA

All rights reserved. No part of this periodical may be reproduced or transmitted in any form or by any means, electronic or mechanical, including photocopying, recording, or any information storage and retrieval system, without permission in writing from the publisher. Permission for printing and for reprinting the material contained herein has been obtained by the publisher. 
as incomes rise above a critical level, people are consuming more calories, typically from energy-dense foods such as cereals, meat, fats, and oils. The same negative trend toward carbohydrate-dominated diets is also being seen where poverty reduces incomes below the critical threshold for food security. In both cases the result is damaging to human health; the reasons for this have been known and understood for centuries and yet the problem of malnutrition persists. Innovative modern science both at the upstream and downstream ends of the research-to-development spectrum needs to be brought to bear globally to tackle this intransigent and highly undervalued problem.

The World Bank projects per capita income in developing countries will grow at an annual rate of 3.4\% from now through 2015. During that same period, the average daily calorie intake in these countries is expected to increase by approximately $200 \mathrm{Kcal}$. Over the past 40 yr, net imports of meat, sugar, wheat, and vegetable oils by developing countries increased by 13 times and are expected to keep growing (FAO, 2004a).

Currently, most African countries have tuber/root or cereal-based diets with starchy staples making up about $60 \%$ of total food consumption (FAOSTAT; http:// faostat.fao.org/default.aspx [verified 31 Dec. 2009]). As per capita income increases in these countries, diets are likely to change in a way similar to those seen in past decades in other developing countries.

Daily calorie intake in European nations over the past 40 yr has increased by about 20\%, from $2960 \mathrm{Kcal}$ to $3340 \mathrm{Kcal}$. As populations in southern Europe, North Africa, and the Middle East have grown more affluent, diets previously rich in fresh fruit and vegetables now incorporate more meat and fat, are higher in calories, and contain greater amounts of high-glycemic carbohydrates (Schmidhuber, 2008). This is particularly an issue in the younger generations under $35 \mathrm{yr}$ of age, where the lessons of good nutritional understanding associated with the mid-20th century global conflict and austerity appear to have been forgotten. Moreover, with increasing urbanization, diets across the world are becoming increasingly similar, characterized by a greater dependency on staple grains (particularly wheat and rice), increased consumption of meat, dairy products, edible oils, salt, and sugar, and a lower intake of dietary fiber (FAO, 2004a).

A balanced human diet is a diverse diet. Humans need to consume an adequate amount of calories, amino acids, fatty acids, minerals, vitamins, and fiber for good health. A balanced diet usually includes both plant and animal products and should include a diverse range of the five major food groups-grains, vegetables, fruits, dairy, and meat - to supply the nutrients necessary to sustain and support healthy growth and activity. Dietary diversity enables people to meet their daily nutritional requirements. As the typical contents of diets worldwide converge and become less diverse, the need to encourage and promote dietary diversification becomes more urgent and necessary.

\section{RELEARNING OLD LESSONS: WHY DIVERSIFY DIETS WITH FRUIT AND VEGETABLES?}

Some efforts to increase nutrient intake have been made by biofortification and nutrient supplementation. Biofortifying staple crops is increasingly used as a complementary strategy for combating micronutrient malnutrition among the poor in developing countries (Bouis, 2002). Maize (Zea mays L.) biofortified with $\beta$-carotene and rice (Oryza sativa L.) biofortified with iron or $\beta$-carotene are examples of efforts to increase micronutrient uptake in staple-heavy diets. Supplements are commonly available in developed countries and can be used to provide the required micronutrients among populations with nutrient deficiencies in developing countries but at a relatively high cost. It has been shown that administration of vitamin A capsules can reduce child mortality by up to $23 \%$ (S. Tanumihardjo, personal communication, 2008).

Although supplementation and fortification programs have been successful in many countries, the majority of the world's population lives in rural areas or peri-urban areas with limited access to, or the income to use, health services, vitamin or mineral supplements, and processed food. Rather, most poor people in rural communities still rely heavily on home-grown produce and inexpensive food purchased from local markets. In these situations, food-based approaches using locally available sources for diet diversification are the most cost effective and quickest means of providing the essential micronutrients needed for health.

The importance of fruits and vegetables in the human diet has been recognized by the World Health Organization (WHO), which promotes and recommends the consumption of at least $400 \mathrm{~g}$ of fruit and vegetables per day to provide the necessary nutrients lacking in other food groups (World Health Organization, 2003a, b). Yet vegetables and fruit are the food groups mostly left out when a person's capacity to obtain more energy-dense food increases.

Underconsumption of fruit and vegetables is among the top ten risk factors leading to micronutrient malnutrition and is associated with the prevalence of chronic diseases (Ezzati et al., 2002; World Health Organization 2003b). Fruit and vegetables contain a range of macroand micronutrients, including provitamin $\mathrm{A}$, iron, and zinc, which contribute to the prevention of malnutrition disorders. Fruits and vegetables also are rich in bioactive phytochemicals that can reduce the risk of chronic diseases such as cancer.

Diets featuring a diversity of vegetables and fruit improve the health of hungry and poor people and affluent consumers alike, as both groups can be malnourished. Consuming fruit and vegetables supplies multiple 
essential nutrients simultaneously, compared to only one or two nutrients provided in supplements or biofortified food. The intrinsic, irreplaceable dietary fiber in fruit and vegetables also promotes good digestion, slows the rate at which sugar is absorbed into the bloodstream (USDA, 2005), and plays a role in reducing the incidence of cancer of the digestive tract (Park et al., 2007). Micronutrients are also important as they act as coenzymes necessary for the metabolism of macronutrients

Micronutrient malnutrition-also referred to as hidden hunger-is seen in food-insecure households in much of the world and can be highlighted as a particular concern in sub-Saharan Africa. It has long been known that micronutrient deficiency inflicts anemia, IQ reduction, and blindness on millions of people. It damages the immune system, resulting in birth defects for thousands of children, complications during pregnancy and childbirth, and ultimately the deaths of an estimated four million children and mothers annually. More generally, it results in largescale loss of energy, intellect, productivity, growth, and economic prospects for millions of people. Furthermore, overcoming or coping with malaria and human immunodeficiency virus/acquired immunodeficiency syndrome (HIV/AIDS) can be facilitated with good nutrition, so the success of HIV/AIDS programs also depends in part on paying more attention to good and balanced nutrition.

Deficiencies of vitamin A, iron, zinc, and iodine are the four main micronutrient deficiencies affecting human health in Africa. Many Africans still consume insufficient amounts of these nutrients, even though they are only required in relatively small quantities. Fruit and vegetables provide substantial amounts of two of these micronutrients, vitamin $A$ and iron, and also provide several other nutrients including vitamin $\mathrm{C}$, vitamin $\mathrm{E}$, phosphorous, calcium, and vitamin $\mathrm{B}$ complex. In addition, fruit and vegetables provide hundreds of naturally occurring substances (e.g., dietary fibers, easily digestible sugars, and antioxidants) that are not commonly available in food supplements and have a high nutrient and low energy density but protect against chronic health conditions (Nyambo et al., 2005). Moreover, many of these micronutrients are not widely available in other foods; almost $90 \%$ of vitamin C in the typical healthy diet comes from fruits and vegetables.

\section{AGRICULTURAL CONSTRAINTS NEEDING INNOVATIVE SOLUTIONS}

Diversifying diets through better access to fruit and vegetables is a challenge global agriculture cannot ignore. Inefficient production methods and a lack of well-adapted seed contribute to poor yields and environmental and health issues, while low quality standards and limited market access thwart opportunities for increasing farmers' income. Research and development is a requirement to counter the bottlenecks to the availability of safe and high quality fruits and vegetables to provide viable, practical, and sustainable solutions for these issues.

\section{Nutrient Content}

Fruit and vegetables provide a range of vitamins and nutrients necessary for human health. Low incomes and limited awareness of the importance of nutrition further constrain diet diversification. Modest improvements in the density of micronutrients in the most commonly consumed fruits and vegetables would increase the benefits of diet diversification. Plant breeding can develop fruit and vegetable lines with increased nutrient contents and concentrations of bioactive compounds (Yang et al., 2007). Food preparation methods can be modified to increase the bioavailability of nutrients to the body (Yang et al., 2002). This is particularly relevant to vegetables where cooking methods can often substantially reduce the nutritional benefits of food, particularly the availability of vitamin C.

Some plant-based nutrients are not in a form that can easily be absorbed by the human body. The body's absorption of plant-based iron is generally lower than that of iron from meat and is greatly influenced by interactions with enhancers and inhibitors. For some vegetables such as amaranth (Amaranthus spp.) and crucifers (Brassicaceae family), cooking can double iron bioavailability and in some cases even increase it by ten times (Yang et al., 2002). Prolonged storage of cooked vegetables will reduce iron bioavailability. Vegetables with different levels of iron bioavailability can be cooked together to enhance the overall iron intake (Yang et al., 2002). In India, where mungbean [Vigna radiata (L.) R. Wilczek], which is low in iron bioavailability, is a staple, the Asian Vegetable Research and Development Center (AVRDC) has designed recipes combining mungbean with tomato (Solanum lycopersicum L.) and pepper (Capsicum spp.), which are high in iron bioavailability, to increase the dish's overall iron bioavailability (Subramanian and Yang, 1998 Bains et al., 2003).

The International Potato Center (CIP) promotes the orange-fleshed sweet potato [Ipomoea batatas (L.) Lam.], which contains high levels of provitamin A carotenoids (100-1,600 $\mu \mathrm{g}$ Retinol Activity Equivalent per $100 \mathrm{~g})$, and the vitamin A formed on consumption is bioavailable (Hagenimana et al., 1999; Van Jaarsveld et al., 2005). Sweet potato is a familiar crop in sub-Saharan Africa, where it is grown for food security, thus farmers already understand sweet potato cultivation methods. This has eased the task of disseminating the nutrient-rich orange-fleshed variety. However, the value of new orange types has had to be established as information on the importance of dietary vitamin $\mathrm{A}$ is lacking and innovative extension methods and educational campaigns, particularly among women's groups, are being undertaken. This innovation has led to the "branding" of orange in society in Mozambique as a high-value, desirable product. Cars, market barrows and 
stalls, shop walls, T-shirts, dresses, headgear, and other clothing have all been used to get the orange-fleshed sweet potato known and desired by adults and children. A recent campaign of this type is almost unknown in the agriculture field. However, knowledge of the nutritional value of sweet potato leaves as a vegetable and its easy means of promulgation is also lacking in sub-Saharan Africa, although well-known in Southeast Asia. Germplasm of leafy sweet potatoes is being screened by AVRDC's Regional Center for Africa in Tanzania for productivity, farmer acceptability, and nutrient quality. A "green" branding campaign may now be needed for such indigenous green leafy vegetables.

AVRDC has also developed high $\beta$-carotene tomato lines using a single $\beta$-carotene gene from wild tomato. The orange-fruited tomato lines contain 3.8 to $6.6 \mathrm{mg}$ of $\beta$-carotene per $100 \mathrm{~g}$ fresh weight compared with 0.6 to $0.9 \mathrm{mg}$ per $100 \mathrm{~g}$ in the common, red-fruited tomato. Heat tolerance and multiple disease resistance have also been bred into the lines. These lines are being promoted for home and school gardens, but this demands innovative research, extension, and education methods as it frequently involves the most disadvantaged sections of society. Nevertheless, the investment in a single packet of improved vegetable seed is an input within the reach of even the poorest farmer and its return in terms of either improved family nutrition or income can be substantive.

Integrated packages of vegetable seeds that provide a balanced source of micronutrients for families year round from only $100 \mathrm{~m}^{2}$ of land have been developed by AVRDC for different regions of the developing world. These "healthy gardening kits" are a central feature of ongoing farmer training programs in Africa, and over 35,000 such kits have been distributed through humanitarian agencies to the victims of major disasters in Africa and Asia since 2000. They include seeds of locally adapted varieties of nutrient-rich, fast-growing vegetables and technical information in local languages on vegetable production, food preparation, and preservation methods. Vegetables have been selected that are commonly grown in many tropical and subtropical less-developed countries, are nutritious, hardy, fast-growing with low input requirements, are and relatively free of pests and diseases. Many of these are indigenous vegetables.

Expanding the existing use of indigenous vegetables can be a very important means of improving family nutrition. In many cases, rural communities have a high rate of indigenous vegetable consumption, which may well average at least $50 \%$ of all vegetables consumed according to AVRDC national surveys in Asia and Africa. However, lack of access to suitable seeds or planting material and knowledge of the nutritional benefits of these often "neglected" crops can be major factors in their failure to be sufficiently exploited in the battle against malnutrition. AVRDC and its partners are presently involved in a 10 yr effort to expand the availability of lines and varieties of these crops and to test whether they may have useful roles in areas beyond the current centers of production and diversity. Associated efforts for mainstreaming such crops in urban supermarkets are also ongoing. Such efforts include crops rich in vitamins and minerals such as amaranth, slippery cabbage [Abelmoschus manihot (L.) Medik.] and its relatives okra [A. esculentus (L.) Moench] and roselle (Hibiscus sabdariffa L.), drumstick tree (Moringa spp.), Malabar spinach (Basella alba L.), African eggplants (Solanum aethiopicum L. and relatives), bitter gourd (Momordica charantia L.), African spider plant (Cleome gynandra L.), giant nightshade (Solanum scabrum Mill. and relatives), and many others.

Amaranth leaves have been a traditional food across Africa for centuries. New, improved lines of amaranth introduced by AVRDC, A. cruentus L., A. hybridus, and $A$. dubius Mart. ex Thell., were released through two local seed companies in East Africa. The new varieties can be harvested as a whole plant in less than a month and are sweeter and softer than the leaves of old varieties, faster to cook, and extremely nutritious. Besides providing the community with cheap, highly nutritious vegetables, heavy demand for the new varieties-known locally as "White Elma" and "Green Gina"-is helping these companies thrive and is contributing to the growth of a viable vegetable seed sector in the region.

In harmony with such efforts on vegetables, the World Agroforestry Centre (ICRAF) has made a broad range of potential introductions of indigenous fruit trees, which often allow harvestable fruit that can be enjoyed throughout a greater proportion of the year. This is in contrast to the condition common in West Africa today of a short term glut followed by many months of no mature fruit. To facilitate these introductions, propagation methods have also been developed for tree improvement and multiplication for key African fruit tree species. The propagation methods developed employ the horticultural techniques of vegetative propagation (rooting of cuttings, grafting, and marcotting) that have the merits of perpetuating over generations desirable traits such as early fruiting, lower branching habit, and dwarfing, elements that contribute to enhanced fruiting on many fruits species. In West Africa for example, these techniques are being applied to species such as Irvingia gabonensis (Aubry-Lecomte ex O'Rorke) Baill., Dacryodes edulis (G. Don) H. J. Lam, Cola spp., Garcinia kola Heckel, Prunus africana (Hook. f.) Kalkman, Pausinystalia johimbe (K. Schum.) Pierre ex Beille, Annikia chlorantha, Ziziphus mauritiana Lam., and Vitellaria paradoxa C. F. Gaertn.. All these species make a very positive contribution to the amelioration of malnutrition particularly the supply of vitamins A and C.

For most rural communities in sub-Saharan Africa, seasonality of fruit ripening is a major cause of the low 
availability and consumption of fruits. ICRAF studies have demonstrated that because different fruit species (indigenous and exotic) ripen at different times, it may be possible to provide farming communities with fruit all year round. For example, in southern Africa, of the 40 indigenous fruits studied, at least one or more species ripened every month throughout the year. Based on such information and nutritional content of the specific fruits (focusing on the major micronutrients such as vitamins $\mathrm{A}$ and $\mathrm{C}$ and iron), site-specific fruit tree portfolios that provide fruits all year round could be developed and tested.

Fruit tree portfolios thus comprise a number of fruit tree species with at least one species yielding fruit at any given time, ensuring fruit availability all year round. Based on nutritional analysis of the fruits, the selected species would be those that have fruits containing the essential micronutrients for maximum nutritional and health benefits. There is a wide selection of indigenous and exotic fruit tree species in all regions of sub-Saharan Africa that can be used in developing of year-round fruit tree portfolios.

Such fruit tree portfolios, packaged with information on threshold nutritional needs of fruits at the family level, can contribute to raising the current low level of fruit consumption in sub-Saharan Africa and also ensure that the WHO standard amounts of fruit consumption for health and well-being are met. In addition, these yearround fruit supplies (fresh or processed) may contribute to mitigating nutritional crises and contribute to reducing micronutrient deficiencies. Moreover, surplus fruit, either fresh or processed, could be an alternative source of income for farming communities.

\section{Climate Adaptation}

Environmental stress is a primary cause of crop losses, reducing average yields for most major fruit and vegetable crops by more than 50\% (Boyer, 1982; Bray et al., 2000). The severity of environmental stress imposed on crops is influenced by climatic uncertainty and change. Extreme geophysical events such as more erratic rainfall patterns, unpredictable high temperature spells, reduced water availability, and the postulated shift in ecological and agro-economic zones will further reduce productivity of fruit and vegetables (FAO, 2004b). Enhancing agro-ecosystem resilience to sustain fruit and vegetable production systems and increase productivity in the face of environmental uncertainty as the climate changes is a prudent and necessary course of action.

AVRDC has made significant contributions to the development of heat-tolerant tomato and Chinese cabbage (Brassica rapa L.) lines and the subsequent release of adapted, tropical varieties worldwide. However, lower yields in heat-tolerant lines remain a concern. Research by the International Crops Research Institute for the SemiArid Tropics (ICRISAT), the International Center for
Agricultural Research in the Dry Areas (ICARDA), and other institutions is in progress to breed drought-tolerant varieties that use water efficiently. Genetic factors underlying drought tolerance in Solanum chilense (Dunal) Reiche and S. pennellii Correll, two wild tomato species indigenous to arid and semiarid environments of South America, are being explored by ICRISAT and AVRDC with the aim of transferring drought tolerance into cultivated tomatoes. Exploration of a large set of representative germplasm from ICRISAT's mandate crops such as pigeonpea [Cajanus cajan (L.) Millsp.] and pearl millet [Pennisetum glaucum (L.) R. Br.] has also revealed considerable variation in salinity tolerance, another potential breeding objective. Marker-assisted selection is being used to screen for desired salt tolerance genes, and attempts to transfer quantitative trait loci (QTLs) and elucidate the genetics of salt tolerance are continuing. ICRAF is presently using conventional participatory fruit tree domestication to take advantage of high phenotypic variation within natural tree stands for selecting superior mother trees suitable for propagation under a range of present or potential environmental conditions.

Adapting agricultural management practices to the production challenges posed by climate variability and change such as limited rainfall and/or irrigation water, flooding, and salinity is vital for future harvests. ICARDA promotes protected agriculture in arid regions with controlled growth environments using less water and fertilizer and careful production timing to improve yield. AVRDC has also developed protected production systems for use with excessive rainfall and grafting to increase flood tolerance. Management strategies have also been developed such as modification of fertilizer application, efficient delivery of water to roots through water-saving irrigation methods, and use of soil amendments to enhance nutrient uptake by plants and improve soil fertility.

Cultivation of indigenous vegetables, fruits, and other underutilized crops is being promoted as many of these plants naturally have higher levels of resilience to environmental stress. These underutilized crops can grow and produce adequately under poor soil conditions, for example in drought-prone or saline areas, and often are more resistant to pests and diseases. In many instances, indigenous vegetables can grow in environments unfit for other crops. They are immediate, strong candidates to withstand the adverse effects of a changing climate.

Since spatial distribution models are not available for the majority of tree species (including fruit tree species), and since information is not available on the ecological limits of most of these species, scientists at ICRAF are developing vegetation maps as useful proxies for the spatial distribution of individual species. By associating indigenous fruit tree species to specific vegetation types, a spatial decision support tool was developed for the highlands of Kenya, allowing fruit tree species selection based on expected ecology 
of sites and species. The same approach is currently being expanded to eastern Africa (Ethiopia, Kenya, Malawi, Uganda, Rwanda, Tanzania, and Zambia) and later globally. At the same time, by modeling the spatial distribution of specific vegetation types, predictions on the future suitable domains for individual fruit species can be made. Where point information is available on the suitability of individual tree species (even as presence-only data sets), it is also possible to combine such point information with the spatial distribution of vegetation types in which the species is known to occur to improve suitability maps and predictions under climate change scenarios. Such information is also required for vegetable species but is presently lacking.

\section{Pests and Pathogens}

Pests and diseases are not new problems in vegetable and fruit production systems. However, in many countries the scope and breadth of phytosanitary precautions have not kept pace with the rising local demands for exotic vegetables as well as global trade, leading to the inadvertent introduction of pests and diseases into new areas. Climate change has altered the dynamics of pest populations, crop resistance, and other factors, creating more complex challenges for the management of pests and diseases. Even in a country such as Australia that practices the most stringent biosecurity measures, the occurrence of Tomato yellow leaf curl virus in urban Brisbane for the very first time in Australia is of significant concern given the devastating nature of the virus globally and the importance of the winter season tomato industry in Queensland (D. Persley, personal communication, 2009).

Integrated pest management and integrated production and protection methods have been applied to prevent pest infestations, control disease outbreaks, and reduce damage. These approaches include improved soil management practices, use of biological control and biopesticides, and breeding varieties resistant to biotic stress. Integrated pest management research has been conducted at the International Institute for Tropical Agriculture (IITA), the International Centre of Insect Physiology and Ecology, ICRISAT, ICARDA, and AVRDC to control legume pod borers (Maruca vitrata, Helicoverpa armigera, etc.) in vegetable legumes. This integrated management method uses major parasitoids — such as the braconid wasp (Apanteles taragamae) and tachinid fly (Nemorilla maculosa) along with Bacillus thuringiensis endotoxins, MaviMNPV (a pod borer-infecting nucleopolyhedrovirus discovered by AVRDC), and synthetic sex pheromones to control the legume pod borer in Southeast Asia and sub-Saharan Africa. Genetically modified brassicas to increase their resistance to diamondback moth (Plutella xylostella) and other secondary lepidopterans and genetically modified cowpea to increase resistance against pod borer (M. vitrata) are under evaluation stage. Hopefully such vegetable varieties will prove to be effective and achieve public acceptance as an alternative to the current biohazardous practices in many developing countries with chronic and injudicious excess spraying of often out-of-date, obsolete, inappropriate, or banned pesticides that are injurious to producers and consumers' health.

Bacterial wilt (caused by Ralstonia solanacearum) can easily kill $100 \%$ of tomato plants in the fields and quickly destroy any hope of harvest from the cultivation. Grafting susceptible tomato varieties onto bacterial wilt-resistant root stock (e.g., tomato variety 'Hawaii 7996') is one effective way to manage the disease. Scientists from the Institute of Agricultural Science of Vietnam learned the grafting technology from AVRDC and introduced the technology to farmers in the Lam Dong province from 2002 to 2004. By 2007, approximately 4000 ha of tomatoes in Lam Dong were cultivated with grafted seedling. The grafting provided Lam Dong farmers with an additional US\$6 million of annual profit (Vinh and Ngo, 2006).

Breeding for resistance is still the best defense against fruit and vegetable diseases. From 2006 to 2008, AVRDC researchers released 21 new lines of pepper in the International Chili Pepper Nursery with resistance to one or more of the following diseases: Cucumber mosaic virus, Chilli veinal mottle virus, Potato virus Y, Tomato mosaic virus, bacterial wilt, and anthracnose. Research is in progress to fine-map and stack Tomato yellow leaf curl virus resistance genes $T y-1, T y-2$, and $T y-3$ to study gene complementation and develop breeding lines with multiple resistance genes.

In the special case of protected agriculture, the warm and humid greenhouse environment is not only suitable for crop production but also is naturally suitable for the development and sustained presence of many pests and diseases. Likewise, overuse, misuse, and careless application of chemical pesticides can result in the accumulation of toxic substances on plants. Decreased pesticide use should thus be desirable as it results in less potential harm to human health and the environment and should help to prevent pesticide resistance building up in target organisms. To address such problems, ICARDA has developed and introduced an Integrated Production and Protection Management (IPPM) program to Central and West Asia and North Africa (CWANA) countries in the Arabian Peninsula, Yemen, Afghanistan, and Pakistan. IPPM is an approach to good management in protected agricultural structures and aims to provide improved means and ways of greenhouse production and crop protection with the use of safe procedures and less chemical pesticides. All factors that can have a direct effect on plant growth and the overall climate of greenhouses, and that may lead to the spread of pests and diseases, are taken into consideration in the IPPM technology approach. Irrigation and fertilization thus are important components of IPPM packages. In Yemen, protected agriculture technologies with an IPPM program were 
introduced and successfully practiced by growers (Mukred et al., 2003). Vegetable plants were healthy and had low incidences of pests and disease (Dubaie et al., 2003). Applying IPPM techniques in Oman also resulted in better yields (ICARDA-APRP, 2002).

\section{Production Methods}

Farmers' limited access to improved, superior varieties and lack of knowledge about the best cultivation and management practices further constrain fruit and vegetable production. Understanding local production systems and the resources available to farmers within these systems is essential to develop technological interventions that will maximize returns to inputs, reduce seasonality, and promote year-round availability of fruit and vegetable products.

Improved production packages for fruit and vegetables have been developed by many agricultural research centers and typically include superior germplasm, balanced fertilization, seedling production, mulching, irrigation, and management of pests and diseases with integrated, sustainable approaches. AVRDC proposes effective rhizosphere management practices to deliver water and nutrients efficiently and effectively to the zone surrounding the roots of plants, where complex interactions occur among the plant, the soil microorganisms, and the soil itself. Effective rhizosphere management is one solution to maximize the productivity of low-input farming systems common in developing countries. Nutrient delivery methods such as starter solutions and rhizosphere soil packets of compost, biomass-derived charcoal, clay, etc., and methods to enhance beneficial soil microbial communities are being evaluated to promote better soil and plant health.

The introduction of superior fruit tree germplasm from Asia into Africa is an important element of improving fruit production. Lack of access to germplasm has remained a key constraint for smallholder agroforestry adoption. By working with local commercial suppliers of seedlings, the ICRAF project will also address the development of smallholder "germplasm delivery systems" for tree species in Africa (Graudal and Lillesø, 2007). A recent example of the success of this approach has been the introduction by ICRAF and ICRISAT of improved Ziziphus mauritiana Lam. germplasm from Asia into Sahelian countries that is grafted onto local rootstocks. This crop, which is rich in vitamin $\mathrm{C}$, grows in exceedingly harsh and dry conditions and is now being commonly marketed in Niger and Mali as "Pomme de Sahel." Crucial to the implementation of such good production practices is the adaptation of the technologies to be suitable for various agro-ecological production environments. Promotion of improved technologies through participatory research trials, training courses, and workshops will encourage dissemination of the adapted technologies to vegetable and fruit producers.
ICRAF is currently developing methods for land health surveillance to systematically identify land health problems and target preventive and rehabilitation programs. Fruit trees are an attractive intervention for rehabilitating degraded land profitably. Part of ICRAF's land health surveillance will diagnose and assess the prevalence of soil nutritional constraints to the growth of fruit production. Infrared and X-ray spectroscopy provide tools that make large area assessments and monitoring feasible by analyzing large numbers of soil and leaf samples at low cost. ICRAF scientists are currently developing and demonstrating protocols for practical application of these tools in surveillance systems.

Soil is the most available and normal growing media for plants. The soil's main functions are to provide anchorage, nutrients, air, and water to plant rooting systems. However, soils may also pose serious limitations to plant growth. Plant diseases caused by soil organisms, unsuitable soil fertility, salt accumulation due to irrigation, unfavorable soil compaction, and poor drainage may cause substantial reductions in fruit and vegetable productivity. In greenhouses, poor soil management almost inevitably increases soil-borne pests such as nematodes and accumulation of salinity. ICARDA, through its research for development program in close collaboration with the National Agricultural Research and Extension Systems (NARES) of many countries in CWANA, has developed, enhanced, and then simplified a number of soilless production techniques for protected agriculture. Soilless culture (hydroponics), when employed on a large scale, can be very challenging and needs informed management and sensitive measurement tools to be effective. However, ICARDA has been innovative and succeeded in enhancing and simplifying such techniques such that they are now suitable for application by small-scale growers. The simplification and consequent lower investment needs are the key innovative features of this technology, making it more acceptable to farmers and improving its impact. A range of alternate hydroponic systems for growing cash crops, including cucumber (Cucumis sativus L.), tomato, pepper, musk melon (C. melo L.), green bean (Phaseolus vulgaris L.), and strawberry (Fragaria $\times$ anannasa), were tested at research stations. Soilless culture has not only shown itself to be a practical solution for many soil problems but also has managed to significantly increase water use efficiency and productivity. Such techniques are now being transferred to growers in many countries.

The vertical soilless production system has been adopted by a number of small-scale growers for production of strawberries and green beans. Up to a five fold increase in yield has been recorded with a reduction of $98 \%$ in water use and $63 \%$ reduction in fertilizer consumption and a reduction of $59 \%$ in general production cost compared with traditional soil beds (Moustafa et al., 
2006). A study on the productivity and quality of cucumber was performed by ICARDA with three different soilless production systems in the United Arab Emirates. The primary production data for cucumber and their comparison with the normal soil bed at the research station show the significant superiority of soilless culture. Soilless systems not only increase yields but also speed up production. Water productivity in the soilless system reached $81.6 \mathrm{~kg}$ $\mathrm{m}^{-3}$ while with soil beds it was only $31.3 \mathrm{~kg} \mathrm{~m}^{-3}$ (Moustafa et al., 2006), thus showing significantly increased water use efficiency.

\section{Transportation and Packaging}

Fruit and vegetables are highly perishable commodities. Postharvest losses in vegetables from field to consumer have been reported to be as high as 50\% in developing countries (Kader, 2003). Inappropriate postharvest handling and packaging and lack of access to adequate transportation infrastructure are some of the reasons for high postharvest losses. Postharvest mishandling and time lags due to the distance from farm to market can cause produce quality and nutritional value to deteriorate, jeopardize food safety, and reduce the value of the products.

It is crucial to disseminate postharvest technologies adapted to suit local conditions and materials and to enhance fruit and vegetable producers' knowledge of good postharvest practices. Better postharvest handling methods can be as simple as harvesting leafy vegetables during the coolest time of day, using smooth instead of rough-surfaced containers to hold produce, and using sturdy containers to avoid crushing when stacked during transportation.

Farmers from the Kiensvay district, Cambodia, used to harvest their tomatoes around noon, let them sit in the sun while waiting for the collector to arrive around $5 \mathrm{pm}$, and then load them in bamboo baskets at about $200 \mathrm{~kg}$ fruits per basket onto cars or trucks. About $10 \mathrm{~kg}$ fruits per basket were lost to physical damage. A training on postharvest technology, conducted by AVRDC, introduced AVRDC tomato line 'CLN1462A', which has high resistance against handling damage. Farmers in the area now harvests their tomatoes at mature green to breaker stage during the cooler part of the day and place the harvested fruits under a shaded area where the fruits are sorted based on maturity. Instead of bamboo basket, containers with smooth surfaces are used during harvest and hauling. The tomatoes are packed in plastic bags at 20 to $22 \mathrm{~kg}$ and careful handling and loading into the transport vehicles are practiced. With the higher price of CLN1462A and the avoided losses during postharvest, farmers increased their net income from $\$ 750$ in 2006 to $\$ 1,750$ in 2007 (AVRDC, 2008).

In Cambodia, Laos, and Vietnam, AVRDC has worked with tomato farmers to evaluate varietal differences in storage quality and resistance to mechanical damage during handling and transport, test the most appropriate packaging, and improve storage practices. To simulate handling hazards, a "drop test" was conducted by dropping a container packed with tomatoes three times from a height of $1.5 \mathrm{~m}$. Fruit of varieties with a higher level of firmness sustained the least damage when a grid polystyrene crate was used with shredded paper as cushioning material (AVRDC, 2008). Precooling improved the storage behavior of tomato. Modified atmosphere packaging and evaporative cooling storage techniques were adapted and optimized for fresh tomato and chili (Capsicum frutescens L.). Low-cost solar driers were fabricated and tested for chili with considerable success. Opportunities for increased use of solar drying techniques in developing countries appear to be radically underexploited at present. Additionally, one of the reasons for the rapid penetration of the tomato varieties 'Tengeru 97' and 'Tanya', developed by AVRDC, which presently dominate the Tanzanian market, can be ascribed to their thicker skins and better transportability to market under local rough road conditions.

\section{Markets}

Domestic and regional markets in developing countries are growing rapidly and are substantially larger in volume and value than global export opportunities. Efficient market-oriented production and effective market interventions therefore offer significant opportunities for poverty alleviation and increased consumption of fruit and vegetables for more vulnerable community members such as women and children in developing countries. However, domestic and regional market supply chains for vegetables tend to be inefficient, long, and complex (Koenig, 2008; J. Lenne and A. Ward, unpublished data, 2008). The major constraints include a high level of postharvest losses; high transaction costs due to inadequate infrastructure; nonexistent or inefficient market information systems; the low bargaining power of farmers; and large seasonal price and volume fluctuations due to undeveloped processing industries. AVRDC, ICRAF, ICRISAT, and ICARDA are addressing these constraints by supporting farmer organizations, enhancing available market information systems to increase farmers' leverage, identifying innovative approaches to link farmers and processors, strengthening farmers' management capabilities and skills, and conducting research to develop or adapt low-cost processing technologies.

In Cameroon, ICRAF has conducted a value chain analysis to identify four important intervention areas for production and consumption of the indigenous fruit "njansang" [Ricinodendron heudelotii (Baill.) Heckel]: (i) the introduction of improved harvest and postharvest techniques that improve product quality; (ii) the grading of produce according to market-determined norms; (iii) the strengthening of farmer producer groups to allow direct negotiations with wholesalers; and (iv) the introduction of a range of services, including market information and 
credit, to help farmers to negotiate higher prices and enable them to store produce for sale to avoid market gluts (Akinnifesi et al., 2008). Action in each of these areas has generated higher value for producers. For example, the prices received for njansang kernels increased by $31 \%$ as a result of collective sales. A similar approach to improve inefficient banana market chains has been successfully adopted in Kenya and Uganda.

\section{Food Contaminants}

Diversifying diets with fruit and vegetables becomes counterproductive if the food itself contains contaminants detrimental to human health. Pesticide residues, microbial contaminants, heavy metals, and toxins are examples of harmful food contaminants that can, in extreme cases, cause death. A study conducted across Ghana's cities showed that $33 \%$ of the lettuce sold in urban markets had residues of banned pesticides and nearly all lettuce showed pathogen levels exceeding common standards (Amoah et al., 2006). Good Agricultural Practices (GAP) to ensure safe production and postharvest management of vegetables and fruit should be emphasized to ensure produce is wholesome and free of contaminants. Such theoretical positions are easy to postulate but prove to be extraordinarily difficult to operationalize in the developing world where lack of knowledge of the implications of injudicious activities such as overspraying are common among small-scale growers.

Reducing pesticide use in fruit and vegetable cultivation helps reduce the level of pesticide residue in crop harvests. Host plant resistance, biological control, sex pheromones, and mechanical controls are some alternatives to the use of pesticides. An integrated pest management strategy to control eggplant fruit and shoot borer developed by AVRDC involves proper field sanitation, prompt disposal of infected shoots throughout the season, installation of traps baited with sex pheromone, and withholding insecticide use to allow proliferation of the pest's natural enemies. This integrated pest management effort resulted in a $70 \%$ reduction of pesticide use in eggplant production in Bangladesh (Alam et al., 2006). Adapting and disseminating the technologies to other crop-producing regions can lead to further reductions in pesticide residues on vegetables and fruit.

Mycotoxin contamination is a widespread problem in developing countries in the tropics (Waliyar et al., 2003). Such toxins are a secondary metabolite produced by species of fungus, for example Aspergillus flavus and A. parasiticus. When ingested with contaminated food the toxins are particularly carcinogenic in humans and often result in liver cancer and other diseases, as they are mutagenic and immunosuppressive. The environment, farming practices, socioeconomic conditions, lack of awareness, inadequate monitoring skills, and processing facilities make the crops and food produced in tropical countries highly vulnerable to mycotoxin contamination (Ortiz et al., 2005; Waliyar et al. 2005, 2008). Groundnuts (Arachis hypogaea L.) and groundnut-based products are particularly susceptible to aflatoxin contamination, although the contamination level in vegetables such as chili and nut crops such as pistachio (Pistacia vera L.) can also be very high. A recent market study in India by ICRISAT has shown that in some samples the level of aflatoxins in chili can be as high as $969 \mu \mathrm{g} \mathrm{kg}^{-1}$, which is a dramatically toxic concentration given that the maximum tolerated level in food is $4 \mu \mathrm{g} \mathrm{kg}^{-1}$ in the European Union and $30 \mu \mathrm{g} \mathrm{kg}^{-1}$ in India (FAO, 2004c). Good Agricultural Practices can significantly reduce the aflatoxin contamination in many crops (Waliyar et al., 2008) and testing is now comparatively simple and cheap (Waliyar et al., 2009).

Information dissemination about mycotoxin contamination is critical, as most farmers and consumers are unaware of the problem. Once awareness has increased, preventative measures can be taken (Singh and Jauhar, 2006). Correct storage after harvest is also important and it is vital that crops are dried to a safe moisture level as quickly as possible.

Threats to human health from heavy metals are can also be a problem and are mainly associated with exposure to lead, cadmium, mercury, and arsenic. Elevated concentrations of heavy metal in agricultural soil and foliar uptake from heavy metals in the atmosphere produced by smokestack and vehicle emissions are sources of heavy metal contamination on vegetables and fruit (Kachenko and Singh, 2006), as is compost composed of contaminated urban waste. A significant proportion of contamination occurs during transport to market or at the point of sale. Urban and peri-urban vegetable production systems are particularly vulnerable.

Research conducted by the CIP-led Consultative Group on International Agricultural Research (CGIAR) challenge program "Urban Harvest" in Kampala, Uganda, showed that leafy vegetables should not be grown near roadsides and that the safest distance to conduct farming activities in the city is more than $30 \mathrm{~m}$ from the edge of the road. Vegetables should be washed thoroughly to remove heavy metals accumulated on the surface and their skins peeled where possible (CIP, 2007). Marshall et al. (2006) recommend washing vegetables twice in clean water to reduce heavy metal contamination. Planting gardens behind houses and other structures could help block some lead, cadmium, and zinc emitted from road vehicles, thus decreasing heavy metal contamination through foliar uptake. Regulation of vehicle emissions and the use of unleaded fuels should be part of the long-term solution to heavy metal contamination in urban and peri-urban vegetable production systems.

In urban areas, domestic users, industry, and commercial enterprises consume large volumes of fresh water and 
in turn generate a large volume of wastewater, which in most developing countries is discharged back into natural water bodies with no or little treatment. Jimenez and Asano (2004) and Keraita et al. (2008) suggested that up to 20 million ha are irrigated globally with untreated, partly treated, diluted, or treated wastewater. A recent global survey found that vegetables are the most common crops produced with diluted or raw wastewater (RaschidSally and Jayakody, 2007). This practice may harm human health due to pathogens (parasitic worms, protozoa, bacteria, and viruses from fecal contamination), heavy metals, pesticide residues, and fertilizers in the wastewater (Qadir et al., 2007). Farmers, consumers, and governmental agencies in many countries are not fully aware of the hazards of irrigation with wastewater. The International Water Management Institute (IWMI) is presently heavily committed to addressing this problem in sensitive crops such as fruit and vegetables and is working on a range of health risk reducing options between farm and table.

To reduce microbial contamination from wastewater irrigation in lettuce production, IWMI studied ceasing irrigation before harvest. The study showed that during the dry season in tropical climates, the method can result in average daily reduction of $0.65 \mathrm{log}$ units of thermotolerant coliforms (Keraita et al., 2007). However, irrigation cessation periods adversely affect the productivity and freshness of the crops, especially in hot climates such as West Africa, while it has more potential in cooler climates (e.g., in Ethiopia). Methods recommended by WHO (2006) to minimize wastewater contamination include primary water treatment, storing reclaimed water, wearing protective clothing to reduce exposure and washing hands and feet to prevent the spread of infection, farmlevel wastewater management such as drip irrigation, and stopping irrigation before harvesting. Thorough washing, peeling, and cooking of vegetables are also important. The efficacy and adoption potential of these and other locally adapted safer practices is under study by IWMI and partners (Drechsel et al., 2008).

AVRDC and IWMI aim to incorporate more indigenous vegetables in urban and peri-urban production systems. Indigenous vegetables are easy to grow, need fewer external inputs such as water, and are often resistant to pests and diseases, needing less pesticide application in the production system. Indigenous vegetable production is expected in the long term to reduce the accumulation of pesticide residues and fertilizer in water bodies.

\section{EXPECTED OUTCOMES OF DIET DIVERSIFICATION}

As the adverse effects of climate change and other production constraints become more apparent, vegetable and fruit farmers will need tools to maintain or increase yield, nutritional quality, and profitability of safe products. Fruit and vegetable farmers in developing countries are usually smallholders, thus often have fewer options and must rely heavily on resources available from their farms or within their communities. Technologies that are simple, affordable, and accessible must be the short-term outcomes of the effort to increase the resilience of fruit and vegetable production systems in less developed countries if the major problem of malnutrition in humans is to be addressed effectively. Crop diversification seems to be a simpler and more easily applied option than biofortification to address this issue. Nevertheless, both approaches need to be seen as complementary as malnutrition is too complex and too overwhelming an issue not to use all possible resources and avenues in ensuring it is eliminated as early as possible.

Implementation of available, improved technologies should result in increased production levels of vegetables and fruits. Supported by good postharvest handling and efficient markets, such efforts are expected to reduce the seasonality of the produce to make it available year long. Eliminating or reducing food contaminants to safe levels and increasing the nutrient content and bioavailability should raise the quality of fruit and vegetables. The medium-term outcome of the effort to diversify diets should be an adequate quantity and quality of safe fruit and vegetables available yearround for human consumption.

Increasing awareness of the importance of nutritious diets and providing access to safe fruit and vegetables will be needed to attain the long-term outcome of diet diversification: to have a healthy, balanced diet fulfilling the recommended per capita consumption rate of $400 \mathrm{~g}$ of fruit and vegetables per day. However, effective development pathways are needed to promote sustainable diet diversification. Stakeholders throughout the production system will benefit from capacity building; infrastructure and facilities will require installation, upgrading, and maintenance. Dissemination and adoption efforts should be achieved in collaboration with local partners and with the participatory involvement of all stakeholders. NARES, the private sector, governmental and nongovernmental organizations, and community-based organizations are potential partners in the development and dissemination pathways of diet diversification with fruit and vegetables.

Fruit and vegetable production and marketing, however, are knowledge-intensive areas of human behavior. Such knowledge can only be generated through supportive agricultural research and development in this very broad range of species. At present, investment in research and development in most of these species to overcome problems of malnutrition and poverty is inadequate and will prevent their potential to be properly expressed. Broadening the current myopic focus of key public sector agencies on only a very small number of food staple species might allow a more effective and equitable investment balance to be achieved. 


\section{CONCLUSIONS}

The need to diversify human diets with fruit and vegetables is an imperative we ignore at our own peril. The health benefits of consuming a well-balanced diet are profound and long-lasting; the impact on the well-being of individuals, families, communities, and economies in all countries and at all income levels cannot be underestimated. With nutritionally improved, pest-resistant fruit and vegetable varieties capable of thriving in increasingly unpredictable environments and with efficient and safe technologies adapted to the needs of farmers and consumers, the economic benefits of fruit and vegetable production and the nutritional advantages of diversified diets can extend deeply into societies all along the fruit and vegetable value chains. Ensuring that smallholders and their families become part of this productive, healthy chain will demand substantive new investments in research and development, a strong commitment to partnerships and communication, and the desire to bring prosperity to the poor and health to all.

\section{REFERENCES}

Akinnifesi, F.K., R.R.B. Leaky, O.C. Ajayi, G. Sileshi, Z. Tchoundjeu, P. Matakala, and F.R. Kwesiga. 2008. Indigenous fruit trees in the tropics: Domestication, utilization and commercialization. CABI Publ., Wallingford, UK.

Alam, S.N., M.I. Hossain, F.M.A. Rouf, R.C. Jhala, M.G. Patel, L.K. Rath, A. Sengupta, K. Baral, A.N. Shylesha, S. Satpathy, T.M. Shivalingaswamy, A. Cork, and N.S. Talekar. 2006. Implementation and promotion of an IPM strategy for control of eggplant fruit and shoot borer in south Asia. Tech. Bull. 36. AVRDC Publ. 06-672. AVRDC - The World Vegetable Center, Shanhua, Taiwan.

Amoah, P., P. Drechsel, R.C. Abaidoo, and W.J. Ntow. 2006. Pesticide and pathogen contamination of vegetables in Ghana's urban markets. Arch. Environ. Contam. Toxicol. 50:1-6.

Asian Vegetable Research and Development Center. 2008. Improving rural livelihoods through development of vegetable based postharvest technologies in Cambodia, Lao PDR and Viet Nam: Evaluation report. Project Final Report Asian Development Bank. AVRDC - The World Vegetable Center, Shanhua, Taiwan.

Bains, K., R.Y. Yang, and S. Shanmugasundaram. 2003. High-iron mungbean recipes for north India. AVRDC Publ. 03-562, AVRDC - The World Vegetable Center, Shanhua, Taiwan.

Bouis, H. 2002. A new tool for fighting micronutrient malnutrition. J. Nutr. 132:491S-494S.

Boyer, J.S. 1982. Plant productivity and environment. Science 218:443-448.

Bray, E.A., J. Bailey-Serres, and E. Weretilnyk. 2000. Responses to abiotic stresses. p. 1158-1249. In W. Gruissem, B. Buchannan, and R. Jones (ed.) Biochem. Mol. Biol. Plants. ASPP, Rockville, MD.

CIP. 2007. Impacts of urban agriculture: Highlights of urban harvest research and development, 2003-2006. Comercial Gráfica Sucre, Lima, Peru.

Drechsel, P., B. Keraita, P. Amoah, R. Abaidoo, L. Raschid Sally, and A. Bahri. 2008. Reducing health risks from wastewater use in urban and peri-urban sub-Saharan Africa: Applying the 2006 WHO guidelines. Water Sci. Technol. 57:1461-1466.

Dubaie, A.H., A.R. Kadasi, and M. Al-Dhubhani. 2003. Integrated production and protection management in cucumber cultivation under plastic houses in Yemen terraces in winter season. ICARDA-APRP Annu. Rep. 2002-2003. ICARDA, Aleppo, Syria.

Ezzati, F., A.D. Lopez, A. Rodgers, S.V. Hoorn, and C.J.L. Murray. 2002. Selected major risk factors and global and regional burden of disease. Lancet 360(9343):1347-1360.

FAO. 2004a. Food insecurity in urban future. Available at http://www.fao.org/newsroom/en/focus/2004/51786/ article_51797en.html (verified 23 Dec. 2009). FAO, Rome.

FAO. 2004b. Proc. Reg. Conf. Asia and the Pacific, 27th, Beijing, China. 17-21 May 2004. FAO, Rome.

FAO. 2004c. Worldwide regulations for mycotoxins in food and feed in 2003. FAO Food Nutr. Pap. 81. FAO, Rome.

Graudal, L., and J.-P.B. Lillesø. 2007 Experiences and future prospects for tree seed supply in agricultural development support - based on lessons learnt in Danida supported programmes, 1965-2005. The Ministry of Foreign Affairs of Denmark, Copenhagen, Denmark.

Hagenimana, V., E.E. Carey, S.T. Gichuki, M.A. Oyunga, and J.K. Imungi. 1999. Carotenoid contents in fresh, dried and processed sweet potato products. Ecol. Food Nutr. 51:91-107.

ICARDA-Arabian Peninsula Regional Program. 2002. Strengthening agricultural research and human resource development in the Arabian Peninsula. ICARDA-APRP, Aleppo, Syria.

Jimenez, B., and T. Asano. 2004. Acknowledge all approaches: The global outlook on reuse. Water 21:32-37.

Kachenko, A.G., and B. Singh. 2006. Heavy metals contamination in vegetables grown in urban and metal smelter contamination sites in Australia. Water Air Soil Pollut. 169:101-123.

Kader, A. 2003. A perspective on postharvest horticulture (19782003). HortScience 38:1004-1008.

Keraita, B., B. Jimenez, and P. Drechsel. 2008. Extent and implications of agricultural reuse of untreated, partly treated, and diluted wastewater in developing countries. CAB Rev. Perspect. Agric. Vet. Sci. Nutr. Nat. Resour. 3:58.

Keraita, B., F. Konradsen, P. Drechsel, and R.C. Abaidoo. 2007. Reducing microbial contamination on wastewater-irrigated lettuce by cessation of irrigation before harvesting. Trop. Med. Int. Health. 12(Suppl.)2:8-14.

Koenig, T., J. Blatt, K. Brakel, K. Kloss, T. Nilges, and F. Woellert 2008. Market-driven development and poverty reduction: A value chain analysis of fresh vegetables in Kenya and Tanzania. SLE Publ. Ser. Humboldt University, Berlin, Germany.

Marshall, F., R. Agarwal, D.T. Lintelo, D.S. Bhupal, R.P.B. Singh, N. Mukherjee, et al. 2006. Heavy metal contamination of vegetables in Delhi. Available at http://www.cseindia. org/programme/health/pdf/conf2006/toxins2_aggarwal2. pdf (verified 23 Dec. 2009).

Moustafa, A.T., S. Oraifan, A. Al Bakry, and A. Nejatian. 2006. Human and nature: Working together for sustainable development of drylands. p. 839-842. In Proc. Int. Conf. on Dryland Development, 8th, Beijing, China. 26-28 Feb. 2006. ICARDA, Aleppo, Syria.

Mukred, A., A.T. Moustafa, A. Al Kirshi, and M. Al Dhubani. 2003. Introduction of protected agriculture into mountain terraces of Yemen. p. 504-511. In Proc. Int. Conf. on Development of Drylands, 7th, Tehran, Iran. 14-17 Sept. 2003. ICARDA, Aleppo, Syria. 
Nyambo, A., A. Nyomora, C.K. Ruffo, and B. Tengnas. 2005. Fruits and nuts, species with potential for Tanzania. Tech. Handb, 34. Regional Land Management Unit, World Agroforestry Center, Nairobi, Kenya.

Ortiz, R., T. Ban, R. Bandyopadhyay, D. Bergvinson, K. Hell, and D. Jeffers. 2005. CGIAR research-for-development program on mycotoxins. p. 44-45. Abstr. of Conf. on Reducing Impact of Mycotoxins in Tropical Agriculture with Emphasis on Health and Trade in Africa. Accra, Ghana. IITA and Myco-Globe.

Park, Y., A.F. Subar, V. Kipnis, F.E. Thompson, T. Mouw, A. Hollenbeck, M.F. Leitzmann, and A. Schatzkin. 2007. Fruit and vegetable intakes and risk of colorectal cancer in the NIHAARP diet and health study. Am. J. Epidemiol. 166:170-180.

Qadir, M., B.R. Sharma, A. Bruggeman, R. Choukr-Allah, and F. Karajeh. 2007. Non-conventional water resources and opportunities for water augmentation to achieve food security in water scarce countries. Agric. Water Manage. 87:2-22.

Raschid-Sally, L., and P. Jayakody. 2007. Understanding the drivers of wastewater agriculture in developing countries. p. 425457. IWMI, London, UK.

Schmidhuber, J. 2008. Food policies, consumption patterns, health concerns and the Mediterranean diet. Proc. of Conf. on Mediterranean Products in the Global Market, Calabria, Italy. 16-17 June 2008. Available at http://aic.ucdavis.edu/calmed/ calmed4/agenda.html (verified 23 Dec. 2009).

Singh, R.J., and P.P. Jauhar. 2006. Genetic resources, chromosome engineering, and crop improvement. CRC Press, Boca Raton, FL.

Subramanian, A.M., and R.Y. Yang. 1998. High-iron mungbean recipes from south Asia. AVRDC Publ. 98-480. AVRDC The World Vegetable Center, Shanhua, Taiwan.

Van Jaarsveld, P.J., M. Faber, S.A. Tanumihardjo, P. Nestel, C.J. Lombard, and A.J. Benade. 2005. Beta-carotene-rich orangefleshed sweet potato improves the vitamin A status of primary school children assessed with the modified-relative-doseresponse test. Am. J. Clin. Nutr. 81:1080-1087.

Vinh, N.Q., and X.C. Ngo. 2006. Grafting and growing tomatoes by grafted seedlings to protect from bacterial wilt (Ralstonia solanacearum) on 3500-4,000 ha each year in Lam Dong
Province, Viet Nam. IAS Research Highlights. Institute of Agricultural Sciences for Southern Viet Nam.

Waliyar, F., P.L. Kumar, A. Traore, B.R. Ntare, B. Diarra, and O. Kodio. 2008. Pre- and postharvest management of aflatoxin contamination in peanuts. p. 209-218. In J. Leslie, R. Bandyopadhyay and A. Visconti (ed.) Mycotoxins detection methods, management, public health and agricultural trade. CABI Publ., Wallingford, UK.

Waliyar, F., S.V. Reddy, T.Y. Reddy, K. Subramanyam, P.Q. Craufurd, and T.R. Wheeler. 2005. Management of aflatoxins in groundnut in southern India. Sum. Proc. Of Int. Peanut Conf. on Prospects and Emerging Opportunities for Peanut Quality and Utilization Technology, Bangkok, Thailand. 9-15 Jan. 2005. Int. Crops. Res. Inst. for the Semi-Arid Tropics, Patancheru, India.

Waliyar, F., S.V. Reddy, K. Subramanyam, T.Y. Reddy, K. Ramadevi, and P.Q. Craufurd. 2003. Importance of mycotoxins in food and feed in India. Aspects Appl. Biol. 68:147-154.

Waliyar, F., S.V. Reddy, and P. Lava Kumar. 2009. Review of immunological methods for the quantification of aflatoxins in peanut and other foods. Peanut Sci. 36:54-59.

World Health Organization. 2003a. Fruit and vegetables promotion initiative. Rep. of the meeting, Geneva, Switzerland. 25-27 Aug. 2003. World Health Organization, Geneva, Switzerland.

World Health Organization. 2003b. Diet, nutrition and the prevention of chronic diseases. Report of a joint WHO/FAO expert consultation. WHO Tech. Rep. Ser. 916. World Health Organization, Geneva, Switzerland.

World Health Organization. 2006. WHO guidelines for the safe use of wastewater, excreta and greywater. p. 25-28. World Health Organization, Geneva, Switzerland.

Yang, R.Y., P.M. Hanson, and T.A. Lumpkin. 2007. Better health through horticulture -AVRDC's approach to improved nutrition of the poor. Acta Hortic. (ISHS) 744:71-78.

Yang, R.Y., S.C.S. Tsou, and T.C. Lee. 2002. Effect of cooking on in vitro iron bioavailability of various vegetables. p. 130142. In T.C. Lee and C.T. Ho (ed.) Bioactive Compounds in Foods: Effect of Processing and Storage. American Chemical Society, Washington, DC. 